\title{
The Importance of Keeping the Island's Vertebrate Fossils in the Public Domain
}

\author{
David W. Krause', Patrick M. O'Connor", Armand \\ H. Rasoamiaramanana"', Gregory A. Buckley ${ }^{\text {IV }}$, David \\ Burney ${ }^{v}$, Matthew T. Carranov", Prithijit S. Chatrath ${ }^{\text {VII, }}$ \\ John J. Flynn vil', Catherine A. Forster', Laurie R. \\ Godfrey $^{\mathrm{I}}$, William L. Jungers', Raymond R. Rogers ${ }^{\mathrm{x}}$, \\ Karen E. Samonds $s^{\mathrm{xI}}$, Elwyn L. Simons ${ }^{\mathrm{VII}}$, Andre R. Wyss ${ }^{\mathrm{xII}}$
}

\section{INTRODUCTION}

The origin of Madagascar's highly endemic vertebrate fauna remains one of the great unsolved mysteries of natural history. From what landmasses did the basal stocks of this unique and imbalanced fauna come? When and how did the ancestral populations arrive on the island? How rapidly did they diversify, and why? The most direct means of addressing these questions, and other enigmas concerning the evolutionary and biogeographic history of Madagascar's vertebrate fauna, is through discovery of fossils from a sequence of well-dated geological horizons. Many fossils relevant to these queries have been discovered by paleontologists in recent years... but many more are being lost to commercial enterprises, both foreign and domestic, that have little or no regard for the scientific significance of fossils. The objectives of this essay are to 1) provide an overview of Madagascar's vertebrate fossil record and its importance, 2) raise awareness concerning the illegal collection, exportation, and sale of vertebrate fossils, and 3) stress the importance of keeping vertebrate fossils from the island in the public domain In light of these issues, we underscore the necessity for development of adequate repositories and support infrastructure in Madagascar to safeguard and display the country's vertebrate fossil collections; doing so would ensure the preservation and appreciation of Madagascar's rich natural heritage for future generations of scientists and Malagasy citizens alike.

\section{MADAGASCAR'S TERRESTRIAL AND FRESHWATER VERTEBRATE FOSSILS}

Numerous Pleistocene (1.8 million years ago [Ma] to 11,500 years ago) and Holocene (11,500 years ago until today) cave sites and swamp deposits scattered across Madagascar have yielded the bones of extinct vertebrates that lived before and
Correspondence:

David W. Krause

Telephone: +31 6314443117

Fax: +31 6314443947

E-mail: David.Krause@stonybrook.edu during human colonization of the island, which began roughly 2,300 years ago. In recent years, paleontologists from a number of foreign institutions (e.g., Duke University, Field Museum, Fordham University, Stony Brook University, University of Massachusetts - Amherst), in collaboration with scientists from the University of Antananarivo, have unearthed the bones of giant tortoises, elephant birds, pygmy hippopotamuses, many extinct species of lemurs, and a variety of other interesting creatures. Although some of these bones are as old as 26,000 years (Late Pleistocene), others have been dated to as recent as 500 years, some 1,800 years after human occupation of the island. The Holocene fossil record also reveals that the geographical distributions of several extant species of lemurs (e.g., bamboo lemurs and indris) were much broader in the recent past.

In contrast, the pre-Pleistocene Cenozoic (65.5-1.8 Ma) fossil record of Malagasy terrestrial and freshwater vertebrates is virtually non-existent, in large part because terrestrial sediments from this interval are rare or extremely difficult to access. The Mesozoic Era, however, has yielded an abundance of vertebrate fossils, from all three of its periods: Triassic (251.0-199.6 Ma), Jurassic (199.6-145.5 $\mathrm{Ma})$, and Cretaceous (145.5-65.5 Ma). Following upon work conducted by various French, Japanese, and Malagasy expeditions that began in 1895, Stony Brook University and the University of Antananarivo have conducted joint paleontological field research in Upper Cretaceous sediments (one horizon at 70 million years old and another slightly older) of the Mahajanga Basin since 1993. This work has resulted in a plethora of well preserved and remarkably complete specimens that have shed considerable new light on the evolution of Cretaceous vertebrates from across the southern supercontinent Gondwana, and from Madagascar
I Department of Anatomical Sciences, Stony Brook University, Stony Brook, New York 11794, U.S.A.

|| Department of Biomedical Sciences, Ohio University, Athens, Ohio 45701, U.S.A.

III Département de Paléontologie, Université d'Antananarivo, Antananarivo (101), Madagascar

IV Evelyn T. Stone University College, Roosevelt University, Chicago, Illinois 60605, U.S.A.

V Department of Conservation, National Tropical Botanical Garden, Kalaheo, Hawaii 96741, U.S.A.

VI Department of Paleobiology, Smithsonian Institution, P.O. Box 37012, NHB E-105, MRC-121, Washington, DC 20013, U.S.A.
VII Department of Biological Anthropology and Anatomy and Primate Center, Duke University, Durham, NC 27705, U.S.A.

VIII Division of Paleontology, American Museum of Natural History, Central Part West at 79th Street, New York, New York 10024, U.S.A.

IX Department of Anthropology, University of Massachusetts, Amherst, Massachusetts 01003, U.S.A.

X Geology Department, Macalester College, St. Paul, Minnesota 55105, U.S.A.

XI Redpath Museum, McGill University, 859 Sherbrooke St. W., Montreal, Quebec H3A 2K6, Canada

XII Department of Earth Science, University of California - Santa Barbara, Santa Barbara, California 93106, U.S.A. 
in particular. The Late Cretaceous Malagasy vertebrate fauna now includes fishes, frogs, turtles, lizards, snakes, crocodiles, non-avian dinosaurs, birds, and mammals. The records of frogs, lizards, birds, and mammals are particularly significant in that they are the first-known, pre-Late Pleistocene occurrences from the island.

Paleontologists from the Field Museum, American Museum of Natural History, University of California at Santa Barbara, and University of Antananarivo have also begun to dramatically improve knowledge of Jurassic and Triassic Malagasy vertebrates. A small collection of fossils of probable Early Jurassic age from a site in the central Morondava Basin includes diverse bony and cartilaginous fishes, non-mammalian synapsids ("mammal-like reptiles"), and various other reptiles (including sauropod and theropod dinosaurs, the oldest members of both groups from the island). Middle Jurassic nonmarine vertebrates from Madagascar were previously known only from fragmentary remains recovered before the end of the 19th century but recent expeditions to these deposits have yielded an impressive assemblage from the southern part of the Mahajanga Basin. At least 13 vertebrate groups are now known from this fauna including fishes, amphibians, reptiles (noteworthy being pterosaurs, theropods, and the earliest known ornithischian dinosaur from Madagascar), and the earliest known tribosphenic mammal, Ambondro mahabo, which has generated debates about the origins of "advanced" (holotherian) mammals. Similarly, recent exploration in Middle to Late Triassic strata of the Morondava Basin has revealed a high diversity of vertebrate fossils, complementing discoveries of various fishes, amphibians, and reptiles made largely by earlier French expeditions. This assemblage contains rhynchosaurs, sphenodontians, a dicynodont, a diverse array of basal cynodonts, and an archosauromorph.

Finally, Permian (299-251 Ma) vertebrate faunas of Madagascar, largely collected by French expeditions to the Isalo region in the 20th century, include atherstoniid fishes, primitive amphibians, a host of cotylosaurian and eosuchian reptiles, and, with the exception of a complete dicynodont skull, fragmentary remains of therapsids.

Figure 1 provides just one example of the extraordinary fossils recently recovered from Madagascar and Figure 2 presents a summary of terrestrial and freshwater fossil vertebrates known from the island-more complete summaries are provided by Burney et al. (2004-Pleistocene and Holocene), Krause (2003 - Cretaceous), and Flynn and Wyss (2003 - Jurassic and Triassic).

\section{WHY ARE MADAGASCAR'S VERTEBRATE FOSSILS SO IMPORTANT?}

Fossils provide the only direct chronicle of the rich vertebrate fauna that once existed on Madagascar. They reveal an evolutionary past that scarcely could have been predicted on the basis of the modern fauna alone. For example, without the fossil record, we would not have evidence that gorilla-sized lemurs, diminutive hippopotamuses, and the heaviest bird of all time inhabited the island only a few hundred years ago or that the Cretaceous vertebrate fauna had closer ties to those on the Indian subcontinent and South America than to that on the closer landmass of Africa.

The Late Cretaceous fossil record from Madagascar is pro-viding the highest quality information on the anatomy and

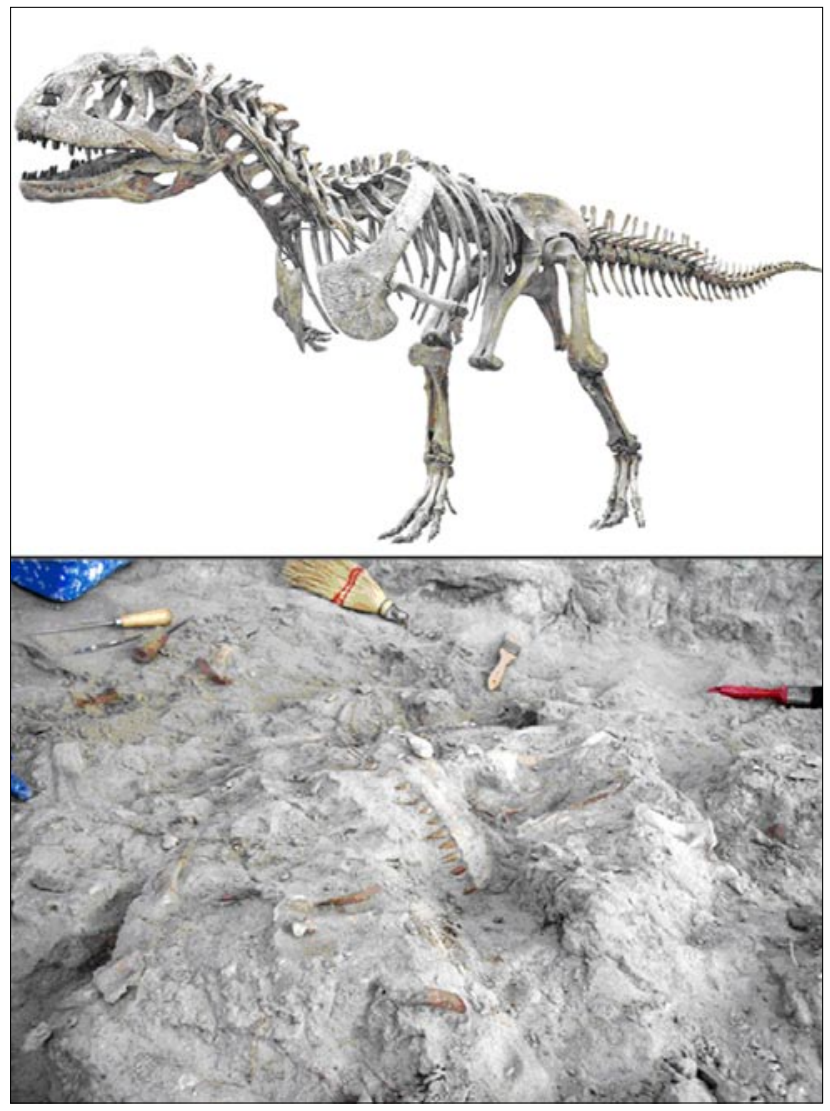

FIGURE 1. An exact replica of the skeleton of the theropod dinosaur Majungatholus atopus from the Late Cretaceous of Madagascar (above), based on a composite of specimens, and the excavation site from which one of the specimens was recovered (below).

relationships of major groups of Gondwanan vertebrate animals. The Jurassic of Madagascar has yielded the earliest known record of tribosphenic mammals, a discovery that has played a strong role in shaping views of early mammalian evolution. For some parts of the fossil record, we already know that Madagascar provides unparalleled insight into ancient animal life because these time intervals are poorly represented elsewhere in the world. For example, at the beginning of the Triassic, a diverse array of archaic vertebrate animals populated the globe. By the end of the period, dinosaurs and mammals had appeared but the record of what transpired in between has been sparse on all continents, and is only now beginning to be revealed by discoveries from Madagascar. The Malagasy fossil record also yields profound insight into the biogeographic origins of the extant fauna of Madagascar, both recent and Iong past extinction patterns (including lessons to be learned concerning maintenance of the modern biodiversity), and the timing, sequence, and environmental and biotic effects of Gondwanan fragmentation.

Despite the views into Madagascar's past provided by these discoveries, it is only a start. Even in the most intensively sampled field areas, it is clear that we have only glimpses of the full diversity of vertebrate animals that once lived on Madagascar. Furthermore, even in these well-studied areas, many species are still represented by only fragmentary or isolated specimens; additional materials must be recovered to learn more about how these animals lived and died, how they 


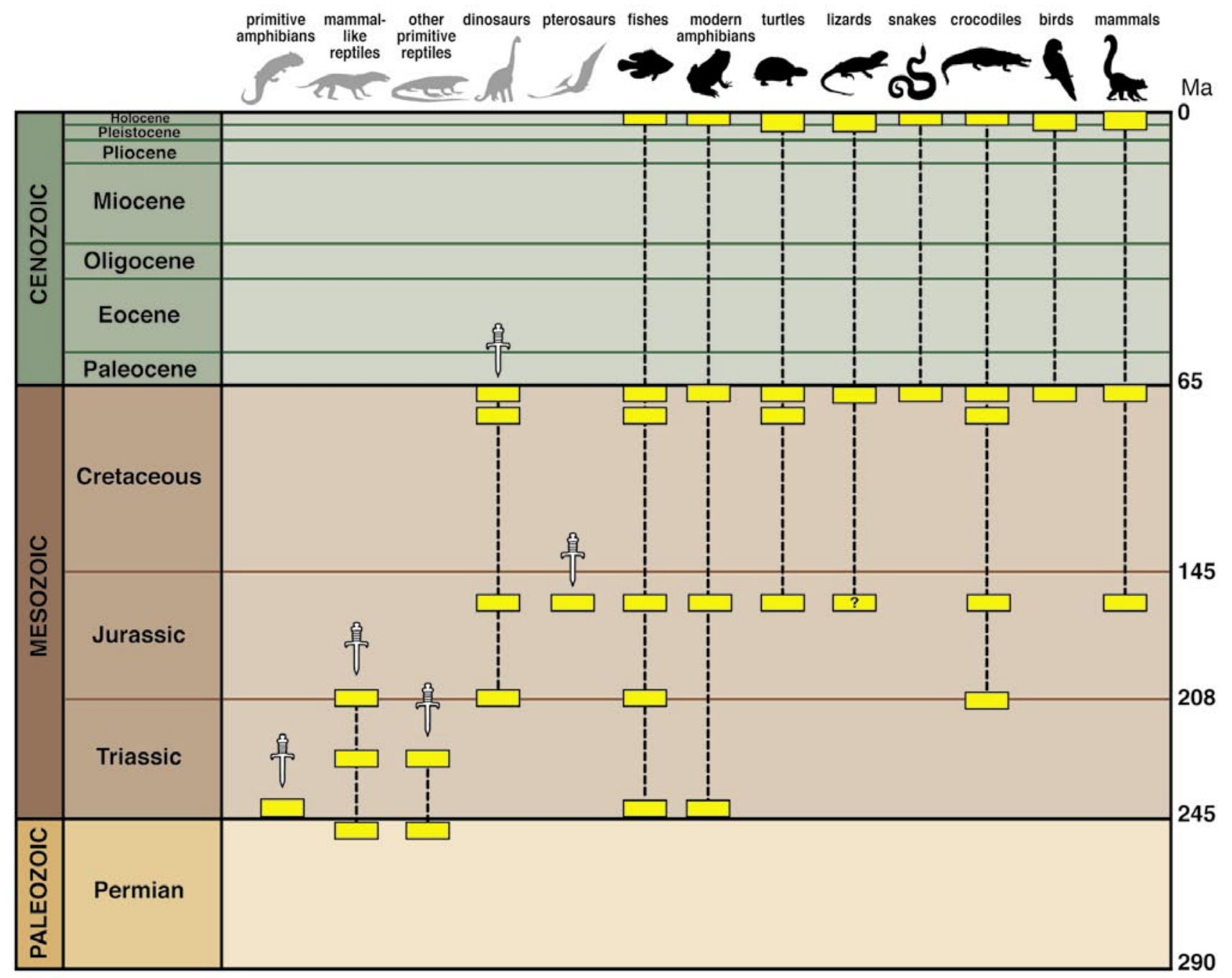

FIGURE 2. Temporal distribution of occurrences (yellow boxes) of terrestrial and freshwater fossil vertebrate groups known from Madagascar. Daggers and gray silhouettes indicate extinct groups.

are related to animals in other parts of the world, and what novel data they reveal concerning broader questions of plate tectonics, biodiversity, and conservation.

\section{THE ILLEGAL COLLECTION AND EXPORTATION OF MALAGASY VERTEBRATE FOSSILS}

Vertebrate fossils collected by trained researchers and technicians are exhumed with extreme care and documentation. Prior to excavation, the sites are carefully mapped and their stratigraphy and sedimentology thoroughly documented. During excavation, the position and orientation of individual bones are duly noted. Rock samples are collected to reveal aspects of depositional history, taphonomy, and paleoecology, and to accurately date the sediments. All scientifically significant fossil specimens in an area are collected, not only those of highprofile taxa (e.g., dinosaurs, primates) or just those parts most valued by private/commercial collectors (e.g., jaws, teeth, skulls, articulated skeletons). Most importantly, all fossils collected on scientific expeditions are maintained in the public domain by accessioning them permanently into museum collections, with all documentation available to current and future researchers.

In order to legally collect vertebrate fossils in, and remove them from, Madagascar, collection and exportation permits must be obtained from the Ministry of Energy and Mines (see Code Minier 2000). Furthermore, current "accords de collaboration" between foreign and Malagasy scientific institutions stipulate that the fossils collected as part of these joint expeditions can be exported for preparation and study but that, upon completion of study, all holotype specimens and one-half of the remaining specimens must be returned to Madagascar. The other half of the specimens are reposited in accredited foreign public museums so that they can be made available to all scientists and, where appropriate, displayed for the worldwide public. As such, all legally collected fossils remain in the public domain, both in and outside of Madagascar. Unfortunately, however, scientifically and educationally priceless fossils are increasingly being pillaged and removed from the public domain by unscrupulous foreign and domestic commercial enterprises. Typically, such fossils find their way into the collections of private owners, and, in turn, important aspects of the natural heritage of Madagascar, and the world, are lost to scientific research and are forever unavailable for the education of current and future generations of the interested public.

Contributors to this article have witnessed multiple cases in which scientifically significant fossils have been destroyed through the poor excavation techniques commonly associated 
with non-scientific collecting. The specimens were not thoroughly consolidated and were carelessly removed from the ground with large picks. We have also observed tell-tale signs of "head-hunting," the practice of removing only the parts of skeletons that will get a high price. Information obtained from local residents indicates that the perpetrators are foreign entities who do not possess accords de collaboration, nor collecting or export permits, and are thus working illegally. Fossils are carelessly removed without regard for critically important location and geological data and then are sold, thereby disassociating them from their geological context and nullifying or markedly diminishing their scientific value. In some cases, rather than collect the fossils themselves, foreign commercial fossil dealers recruit residents living in fossil-rich areas to collect specimens, bring them to pre-arranged meeting places, and sell them, for the equivalent of pennies (providing a small increment of much-needed money to the desperately poor). These fossils are similarly poorly and improperly taken from the ground. Such activity has even resulted in the destruction of fossils, or parts of fossils, while in the process of being legally collected by scientific teams. Whether collected by them or purchased from local residents, the fossil dealers privately sell the fossils abroad, acquiring major ill-gotten profits, while removing the fossils from the public domain.

Many vertebrate fossils are sold in artisans' markets throughout Madagascar, but this practice is particularly rampant in the capital Antananarivo, especially at one site near the Ivato International Airport. Tourists have the opportunity to purchase a range of fossils, among the most common being dinosaur bones from the Jurassic of the Morondava and Mahajanga basins. The bones come in various forms: some consist of complete, or nearly complete, isolated elements, usually vertebrae and teeth; others are bones, usually large sauropod vertebrae, that have been hollowed out and polished to make ashtrays; and yet others are polished into spheres (up to 4 inches in diameter!) to make a game of solitaire utilizing 37 spheres placed on a hardwood board or the traditional Malagasy game "Fanarona", which requires 35 spheres. In some cases, we have been approached, in Antananarivo, in our field camps, and elsewhere, to purchase fossils, both already exhumed (and therefore lacking contextual data) and in situ. Many other fossils from Madagascar are exported and frequently sold on the internet (e.g., www. ebay.com, www.mcculloughfossils.com, www.cornishcrispa. com), in auction houses (e.g., Bonhams and Butterfields Los Angeles Gallery), at gem and mineral shows (e.g., Tucson Gem and Mineral Show), and in rock shops (e.g., Paleoguy's Rock Shop). Indeed, it takes little effort to find illegally collected and exported specimens of vertebrate fossils from Madagascar for sale. Brief searches conducted recently on the internet revealed several examples of not only isolated bones, teeth, and coprolites but also a nearly complete and well-preserved skeleton of a dinosaur. One seller advertised coasters made from sectioned Malagasy dinosaur bone. Elephant bird eggs, in varying states of completeness, are also commonly available. It is impossible to know how many scientifically valuable specimens have been lost due to these various activities, and to predict how many more will be lost in the future.

The rationale provided by commercial enterprises for buying and selling fossils is exemplified by a statement on one of the websites operated by fossil dealers ("Two Guys Fossils": http://www.twoguysfossils.com/), who provide four reasons: 1) "A fossil is a piece of history that, in many cases, will become a family heirloom;" 2) "As a straightforward investment opportunity, fossils outperform many other options;" 3) "A fossil is a lowmaintenance investment;" and 4) "Fossils are functional pieces of art." It is crucial to note that none of these reasons involve science or education; fossils are regarded solely as personal investments and/or as objects of art. No value is placed on retaining the geological context of specimens or in keeping such specimens in the public domain, where scientists can study them or where the public can appreciate them. Also lacking is any acknowledgment of the importance of these specimens to the natural heritage of our planet and their country of origin.

\section{PRESERVING MADAGASCAR'S FOSSILS FOR EVERYONE}

Madagascar's vertebrate fossil resources - currently being lost to illegal but largely unchecked commercial exploitation - must be preserved and protected. It is imperative that they remain in the public domain. If fossils are simply regarded as curios and "objets d'art," that is all they will ever be - commodities regarded only as mysterious or pretty. But there is much more to fossils. Fossils were once parts of living animals and thus yield crucial information about past life on this planet, how extinct animals lived, died, and evolved, and how they interacted with each other and their environment. Data derived from vertebrate fossils are crucial for revealing phylogenetic and biogeographic relationships to other animals on the planet; these data in turn can be used to test hypotheses about the origins of the modern Malagasy fauna and about the timing and effects of Gondwanan fragmentation. They already underscore the need for conservation in that they demonstrate that the geographic distributions of many extant taxa have shrunk drastically since human colonization of the island.

These aspects of Earth history are important for science and fascinating to people of all ages and all cultures, but can only be revealed or independently tested if fossils are excavated with extreme care, if data on their geological context are collected, if they are carefully removed from the rock by skilled and experienced technicians, if they are studied by trained scientists, and if the information derived from them is published in widely accessible scientific or popular books, magazines, or journals. Only if fossils are curated and housed in a public institution (such as a museum or university) can there be reasonable assurance that they will be available to future generations of researchers, educators, students, and the general public. These specimens become all the more significant as new discoveries are made and new techniques for studying them are developed.

Each and every fossil has a story to tell, and these stories from Madagascar's history will be forever lost if the island's fossils are torn from the ground in haste, sold into private collections, and left unstudied. Perhaps most disheartening is the fact that the Malagasy people will lose their opportunity to learn about these fascinating tales themselves if their unique fossil heritage is sold to the highest bidder. The value of fossils as sources of scientific information to unravel the mysteries of past life far outweighs any monetary value that is artificially, illegally, and inappropriately placed upon them by unscrupulous fossil dealers. Madagascar's fossils do not belong on mantelpieces and coffee tables in private homes and offices of the 
world's wealthy to be enjoyed by a few. They instead must be protected in publicly-accessible institutions, in Madagascar and elsewhere.

The woeful state of facilities for storage and display of fossil specimens in Madagascar itself also needs to be addressed. Public research institutions such as the University of Antananarivo are in dire need of a state-of-the-art collections facility to safely store and maintain vertebrate fossils. Correspondingly, Madagascar would be well served if a national museum was built to display the educationally most significant fossils that have already been collected, and those to be collected in the future. Only then can the rich natural heritage of this unique island be fully appreciated by its own citizens, as well as foreign visitors.

\section{ACKNOWLEDGEMENTS}

We thank Audrey Tiernan of Newsday for Figure 1 (top), Luci Betti-Nash for Figure 2, and Urs Thalman and an anonymous reviewer for comments on the manuscript.

\section{REFERENCES}

Burney, D.A., Burney, L.P., Godfrey, L.R., Jungers, W.L., Goodman, S.M., Wright, H.T., and Jull, A.J.T. 2004. A chronology of late prehistoric Madagascar. Journal of Human Evolution 47: 25-63

Flynn, J.J., and Wyss, A. 2003. Mesozoic Terrestrial Vertebrate Faunas: The Early History of Madagascar's Vertebrate Diversity. In: The Natural History of Madagascar, S.M. Goodman and J.P. Benstead (eds.), pp 34-40. University of Chicago Press, Chicago.

Krause, D.W. 2003. Late Cretaceous Vertebrates from Madagascar: A Window into Gondwanan Biogeography at the End of the Age of Dinosaurs. In: The Natural History of Madagascar, S.M. Goodman and J.P. Benstead (eds.), pp 40-47. University of Chicago Press, Chicago.

MINISTÈRE DE L'ENERGIE ET DES MINES. 2000. Code Minier. Madprint, 133 pp. 